environmental factors of which we are ignorant, "or, in my own case, about which I deceive myself or suffer misunderstanding" (page 92). Given this fact (of "differential constitutional luck"), is there a "normative message" about how one should think, live and act (page 92)? It is suggested that working this out is one of the main tasks of the book. And the answer is largely that we "could be easier on the people around us", whilst at the same time recognizing that constitutional luck does not make us "helpless, unthreatening, or eager to change" (page 93). Professor Care is not unaware of the real world, but I wonder if the whole thrust of his message boils down simply to the biblical injunction to "judge not"? This includes, for Care, not judging oneself (too harshly anyway). My concern is that, whilst it is well demonstrated that we are flawed, our need to make judgments - sometimes of a highly critical kind - is not given enough weight. Moreover, if the philosophical issues surrounding the necessity for judgments of value are stirred up, they are not settled in these pages.

The middle three chapters (if I can paraphrase) argue respectively: that when we judge others we do so from within our value systems, which involves imposing our own value judgments; that we are not (as is commonly supposed) wholly rational and "in-control" agents, but are subject to constitutional luck; and, that when it comes to justice, we should be treated as individuals with differences. This is all fine and dandy, but it struck me (as a psychiatrist) that I should still recommend compulsory detention of the next person I assess in the police cells who is expressing violent intentions on the basis of psychotic symptoms. This sort of reality is hardly addressed in the book.

Instead, after numerous intimations, we are treated in the final chapter to a panegyric on the Twelve Steps of Alcoholics Anonymous (AA). Through AA's "many practices, steps, patient people, weird and funny stories, and endless bad coffee" people are enabled to live with their pasts and "achieve a sort of inner calm" (page 153). Well, but it doesn't work for everyone (which Care knows), and what about a close confiding relationship, Zen Buddhism, or Confession in the Roman Catholic Church, with more or less bad coffee? Why is AA here? And what is the book really about? AA?
This is perhaps too harsh, because the book is well written and interesting. Themes which engaged me included much of the discussion of alcoholism and the attitude we should take towards it and other psychiatric disorders. Nevertheless, some of this amounted to tilting at windmills (who would "demand" that someone with mere shyness should be treated (page 86)?). Of central importance, I thought, was much of the analysis of what it is to be a person and the normativity involved in our use of the concept. The conception we have of the person underlies all sorts of other attitudes (to death, for example). "Person-to-person fairness" and the need for "positive other-regarding attitudes of tolerance and generosity" (page 101) are clearly laudable and would not go amiss in medical practice.

I (sadly) cannot recommend the book as an important work in medical ethics. Those with an interest in the concept of the person and issues surrounding psychology and mental health might wish to dip into it. Advocates of AA will enjoy chapter five; philosophers might prefer the middle chapters.

JULIAN C HUGHES

Department of Old Age Psychiatry, Fair Mile Hospital, Cholsey, Oxfordshire

\section{Caring: Nurses, Women and Ethics}

\section{Helga Kuhse, Oxford, Blackwell, 1997, 296 pages, US\$21.95 (pb).}

Writing from her feminist perspective, the author offers timely and provocative insights regarding issues of concern to nurses, physicians and society more generally. The author's arguments are well crafted, and the text is eminently readable. At the same time, there are numerous points on which further comment would be desirable; four such points can be addressed briefly here.

1 Kuhse writes that there appear to be no good reasons justifying a role for nurses as subservient to doctors or medicine; "subservient" is here understood as "inferior" with reference to moral authority. Its use is grounded in a cursory sketch of nursing history and review of several metaphors ("woman $=$ wife/mother $/$ helpmate to man = nurse = helpmate to doctor"; "nurse = dutiful soldier $=$ unthinking machine"). In this context, Kuhse argues strongly against continuance of any subservient nursing posture (particularly as defended by Newton, 1981), noting first that this will cause more harm than benefit to patients, even as it could contribute to the demoralization of nurses. Further, a distinction must be made between the physician's medical and ethical authority. While the nurse might be bound, prima facie, to accept a medical judgment, that response provides insufficient reason to accept the physician's judgment qua ethical as superior to the judgment of the nurse qua ethical.

Missing here is exploration of an alternate contemporary concept, that of the health care team, particularly as concerns collective moral decisionmaking and/or moral consensus building. Can team advocacy, even granting its difficulty of implementation, not serve the patient's and the nurse's interests more successfully than nurse-doctor competition concerning moral authority? Missing here as well is reference to the limit, if any, regarding the moral authority of the patients; will it ever be subservient to the moral authority of the doctor, or the nurse, for that matter?

2 Kuhse argues that nursing ethics should be grounded in caring and impartiality "in the context of a universally accessible moral language of principles, rights or rules and, at times, legislation".

Basic here is the author's concept of a "minimum conception of ethics" and her understanding of the development of feminism (commencing with Gilligan à la "caring"). Confident in her view that "any association between gender and the moral approach [is more likely to be based] in historical and cultural conditions", the author provides critiques of several moral approaches: traditional ethics, "principles and rules", and "partialism" as replacing "impartialism". The discussion concludes with the view that women should accept a morality which embraces the concepts expressed above.

Of particular value in the nursing ethics portion of the text which follows is Kuhse's detailed criticism of Noddings's work (Caring: $A$ Feminine Approach to Ethics and Moral Education, 1984). Kuhse shares Noddings's view that "caring" is essential in grounding nursing ethics. Contrary to Noddings, however, Kuhse argues for "dispositional caring": a "willingness and openness to apprehend the 
health-related reality of the other" where the other is recognised as a "particular" with individual needs, beliefs, etc. In the end, having explored the limitations of "caring" as a sufficient condition here, the author concludes that "impartiality" is also required. While an ethic set out in these terms should be considered acceptable by both men and women, additional specification is needed in the case of women so as to include attention to the historical circumstances of the relations between women and men, nurses and doctors.

The author's argumentation here could well be complemented by analysis pertinent to that situation in which men, as well as women, are members of the nursing profession. In the US and Canada, for example, the number of male nurses is growing; how will Kuhse's position serve their needs? Further, and again within the healthcare team-practice context, how will the two views of an ethic based on caring and impartiality (doctor, nurse) be reconciled and implemented to the benefit of all concerned? Can the approach suggested contribute to development of the team's moral authority, not to say development of complementary roles at bedside and in health care policy formulation?

3 Kuhse writes that individual nurses should not only "share formal responsibility in making end-of-life decisions with doctors;" they should also "take responsibility" with reference to other relevant activity, including "provision of voluntary euthanasia and assisted suicide".

The social debate on the moral acceptability of the latter activities continues; Kuhse's partial reiteration of it will certainly not be universally persuasive. As to nurses' role here, a case could be made that they could function well within the author's proposed ethic while yet eschewing responsibility for provision of these two activities. Once again, in terms of decision-making and the activities proposed above, reference to team practice, in contrast to that provided by separate individuals, should be considered.

4 Kuhse writes that nursing is a "slumbering giant who lacks the assertiveness and courage to do what, clearly, it ought to be doing" in providing appropriate terminal care for patients.

The author's more general point is that the profession must work collectively for systemic change so that nurses will have the formal moral authority already discussed. In the case of voluntary euthanasia and assisted suicide, this may require further research; in the wider context, concerted political action will be necessary.

Left unexplored here is the real difference between any ethical obligation of an individual nurse and the ethical obligation of the group to which that nurse belongs; real difference also obtains between what may be acceptable, morally and legally. For other more compelling reasons the nursing profession might well refuse to sanction voluntary euthanasia, even though individual members of the profession might be engaged in such activity. Still, the author's query regarding the profession's stance in this area has merit; it deserves a response.

Overall, the book is well written and helpful, not least in terms of its careful notation and extensive bibliography. Of particular note is the author's contribution to the caring-justice debate, and her challenges to certain status quo positions within it. That being said, further discussion of the relationship between nurses' autonomy and nurses' membership on health care teams is urgently required, especially by North American readers. No doubt, however, readers' experience with this volume will raise favourable expectations regarding the author's future contributions in this area.

ABBYANN LYNCH

Ethics in Health Care Associates Toronto, Canada

\section{Leaky Bodies and Boundaries: Feminism, Postmodernism and (Bio)Ethics}

Margrit Shildrick, London, Routledge, 1997, 252 pages, $£ 45$ (hb), £14.95 (pb).

This is a book with several theses, some necessarily more novel and important than others. In no particular orderwhich is how they emerge in the book-some of them are as follows:

- (1) Western ethics links moral agency with transcendent disembodiment and lays great stress on autonomy;

- (2) Because women are identified with the body, their agency is there- fore thought to be impaired, a⿳⺈. their autonomy imperfect;

- (3) This impairment is exacerbat $\overrightarrow{\vec{F}} \mathrm{~d}$ by male fear of female bodies fas "leaky", as lacking secure boundaries;

- (4) A feminist ethics, drawing $\frac{\rho}{\delta^{n}}$ postmodern and poststructumal thought, will seek to deconstrot these "secure" categories in favour of a multiplicity of meanings, actually welcoming "leakiness" in anatysis;

- (5) New reproductive technolog exemplify the tension between sựh a feminist analysis and the closed world of traditional medical ethicis

is

Many of these theses arise from premises which seem inadequatey thought through. For example, (4) represents a strangely fatalistic formcof biological determinism for a femintst to adopt. Because women's bodies åre "leaky", must feminist thought be conditioned by that biological truth? And of course claim (4) is also prey 50 the usual problem about any ontological relativism. Shildrick writes that "truth itself is constructed, not disc ered" (page 22)-except, presumaly, that particular truth? In fact Shildrok wavers between highlighting historięal misconceptions about female bodies - many of them fascinating, in passing - and denying that there 奀e any biological givens. But if there arie no facts in biology, then there canñ be any misconceptions about the facfs.

Shildrick disclaims any intention $\exists$ o create a narrative structure to exposition, so that her postmodenn message becomes the medium as we 1 . There is nothing particularly new, or even postmodern about this: Margaret Fuller chose the same tactic in Woman in the Nineteenth Centu다y (1845). Because the argument of the book is not coherently sequential, anod because the style is very heavy, reader emerges with a sense of frustration at opportunities lost. Few readers will stay the course, I fear, particulaly because the intended audience is no means clear. Most medical ethicrots will find too little application here, too much generalisation about the sष्pposed methodological staleness of ghe discipline, and far too much unfandiar postmodern theory. Most femirist theorists will find the discussion of postmodern vision of the individualas subject already familiar from Luce twigaray, Judith Butler and others.

The task of arranging a meethg of minds between the two-medical ethics and feminism, including 